\title{
Knowledge on cervical cancer and screening tests among women at two reference hospitals in Yaounde, Cameroon
}

\author{
Bernard WABO ${ }^{1}$, Dickson Shey NSAGHA ${ }^{2}$, Theophile NANA ${ }^{3}$, Benjamin David \\ Thumamo POKAM ${ }^{1 *}$, Gaitan Fabrice NJIOMENIE ${ }^{1,4}$, Wabo Prisca GUEMDJOM ${ }^{2}$ and \\ Jules Clément Nguedia ASSOB ${ }^{1}$
}

\author{
${ }^{1}$ Department of Medical Laboratory Science, Faculty of Health Sciences, University of Buea, Buea, Cameroon. \\ ${ }^{2}$ Department of Public Health and Hygiene, Faculty of Health Sciences, University of Buea, Buea, Cameroon. \\ ${ }^{3}$ Department of Obstetrics and Gynaecology, Faculty of Health Sciences, University of Buea, Buea, Cameroon. \\ ${ }^{4}$ Department of Infectious and Tropical Medicine, University of Antwerp, Belgium. \\ *Corresponding author;E-mail: thumamo@yahoo.fr
}

\begin{abstract}
Cervical cancer is the second cause of women cancer in Cameroon. This study was conducted to assess the knowledge on cervical cancer and screening tests among women at two reference hospitals in Yaoundé, which will contribute to reinforce cervical cancer prevention. A cross-sectional study conducted in two reference hospitals in Yaoundé included 523 sexually active women aged 25-65 years. Each consenting woman filled a self-administered questionnaire and data on socio-demographic characteristics, knowledge on cervical cancer and screening tests collected. Data obtained were analysed using descriptive statistics. A total of 508/523(97.1\%) participants had heard of cervical cancer. According to 167/523(31.9\%) participants, Human papilloma virus was the causative agent. The media was the main source of information as reported by336/523(64.2\%) participants. Also 209/523(40.0\%) participants had previously been screened and in $135 / 523(25.8 \%)$ cases, the lack of information was the main barriers for screening. We found 490/523(93.7\%) participants with poor a knowledge of the disease. Poor knowledge on cervical cancer was observed in this study. Educational programmes and media information should be used to improve women's knowledge and awareness of the disease for a successful cervical cancer screening and prevention.
\end{abstract}

(C) 2019 International Formulae Group. All rights reserved

Keywords: Cervical cancer, awareness, screening tests, barriers, knowledge score.

\section{INTRODUCTION}

Cervical cancer is the fourth cancer of women world-wide with an estimated 570000 new cases in 2018, representing 6.6\% incidence and $7.5 \%$ mortality (WHO, 2018). It is estimated that about $83 \%$ of the cases occur in low income countries, representing $15 \%$ of female deaths annually (Ekane et al., 2015). According to the Information Centre
/International Agency for Research on Cancer (ICO/IARC) in Cameroon, 1993 women are diagnosed every year and 1120 die from cervical cancer ranking it as the second most frequent cancer in the country (Bruni et al., 2017).

Human papilloma virus (HPV) infection is the primary cause of cervical cancer. It is documented that the majority of 
sexually active women acquire HPV soon after sexual debut and the peak prevalence observed in young women (Mbulawa et al., 2015). HPV infection is often asymptomatic and can regress or progress to invasive cancer depending on the immune system (Ghittoni et al., 2015). HPV is responsible for $99 \%$ of cervical cancer and accounts for approximately half of the infection related burden of cancer in women (Kassa, 2018). HPV-16 and 18 types are associated with 87\% of the total cervical cancer (Sah et al., 2018).

Cervical cancer is a deadly disease once it reaches the invasive stage. Of all existing female genital tract cancers, cervical cancer is the only preventable cancer if detected in the early stages. Population-based screening with Pap smear is an important secondary preventive measure for cervical cancer that leads to a high-cure rate among cervical cancer patients (Shah et al., 2012). Conventionally, Pap smear, combined with treatment of cervical pre-cancerous lesions and early-stage cancer, has been successful in preventing up to $80 \%$ of invasive cervical cancer cases in the developed world (Toye et al., 2017). Unfortunately, cervical cytology is not a feasible method of screening in many African countries given the required level of medical and laboratory infrastructure and trained personnel, multiple return visits with poor patient tracking strategies, and availability of such services are often limited to capital cities (Finocchario-Kessler et al., 2016).

Increasing women's knowledge of cervical cancer and preventive health-seeking behaviour can have a great impact on cervical cancer incidence and mortality (Der et al., 2018). Cameroon has a disproportionately high burden of cervical cancer due to the low awareness that the disease is preventable with prophylactic vaccines, lack of screening and treatment of pre-cancerous lesions, and high prevalence of human immunodeficiency virus (HIV) (Ogembo et al., 2014). This study aimed at assessing the level of knowledge of women on cervical cancer and screening tests that will help improve prevention of the disease in the city of Yaoundé (Cameroon).

\section{MATERIALS AND METHODS} Study design

This was a cross-sectional study conducted in Yaoundé the capital city of Cameroon from October to November 2018. Two reference hospitals were purposely selected namely the Yaoundé University Teaching Hospital (YUTH) and Yaoundé Gynaeco-Obstetric and Paediatric Hospital (YGOPH).

Included in the current study were sexually active/asymptomatic women aged 25-65 years visiting the gynaecologic clinics of the selected hospitals for free cervical cancer screening, routine gynaecologic checkup, patient relatives or patients admitted on referral from other hospitals. Women with existing precancerous/cancerous lesions, history of gynaecologic malignancies and on cancer therapy were excluded from the study.

\section{Collection tools}

A structured, self-administered questionnaire containing multiple-choice questions adapted from Toye et al. (2017) model and frequently asked questions on cervical cancer was designed to contain 4 sections. Section 1 included questions on socio-demographic characteristics, section 2 included questions on awareness and source of information on cervical cancer; section 3 included questions on screening tests and the section 4 asked questions on knowledge of risk factors, symptoms and treatment of cervical cancer. The questionnaire was written in simple French and English in such a way that each participant could independently answer and be administered with the help of two trained research assistants. The questionnaire was pretested using volunteers from different hospital to ensure validity, willingness to participate in the study afterwards necessary corrections were made.

\section{Data collection procedures}

The aim of the study was clearly explained to the participants who were invited to take part in the study. Participants fulfilling the inclusion criteria were requested to fill an informed consent sheet. An identification 
code was given to ensure confidentiality. Participation was voluntary and enrolled women could withdraw at any time during the study without losing their right to medical care. No woman was allowed to participate more than once. Data collected were daily checked for completeness by the researcher.

\section{Sample size calculation}

Purposive sampling technique was used to recruit all eligible participants within 2 weeks in the respective hospitals. We recruited 252 participants from the YUTH and 271 from the YGOPH. Consenting women were consecutively recruited for the study.

\section{Data management and analysis}

Data obtained were entered into Microsoft Excel, clean up and analysed using SPSS version 20. Descriptive statistics: mean and standard deviation were used for continuous variables and frequency and percentages for categorical variables.

Questions regarding specific knowledge on cervical cancer risk factors, symptoms, prevention and treatment were considered to create the specific knowledge score. One mark was attributed to each correct answer and 0 for a wrong one. The specific knowledge score was considered poor for less than $50 \%$ correct answers, satisfactory for 51$79 \%$ correct answers, good for $80-99 \%$ correct answers and excellent for all correct answers. The specific knowledge questions were later grouped to determine the overall knowledge score of participants. Modified Bloom's cut off points was used for assessment with a score of $80-100 \%$ of correct responses equivalent to a good knowledge, a score of $50-79 \%$ equivalent to a satisfactory knowledge and a poor knowledge for a score of less than $50 \%$ of the correct responses. For this study, the respective knowledge levels were: $0-17$ for poor, $18-28$ for satisfactory, 29- 35 for good (Abdullahi et al., 2016).

\section{Ethical considerations}

The aim of the study was clearly explained to participants; each woman was invited to sign a written informed consent form and data obtained from them kept secret. The study was approved by the ethical committee of the Faculty of Heath SciencesInstitutional Review Board of the University of Buea, Cameroon $\left(\mathrm{N}^{\circ}\right.$ : 2018/0254/UB/SG/IRB/FHS) and the administrative authorization obtained from the respective hospital Directors.

\section{RESULTS}

We recorded for this study 252/523(48.2\%) participants from the YUTH and $271 / 523(51.8 \%)$ others from the YGOPH. They were 25-65 years old (mean 41.3+/-10.7 $\mathrm{SD})$. The socio-demographic characteristics shown on Table 1 reveals that 248/523(47.5\%) participants were aged 25-38 years, 320/523 (61.2\%) were married, $177 / 523(33.8 \%)$ had no formal activity and 234/523(44.7\%) had attended the secondary school.

The awareness and barriers to cervical cancer is shown on Table 2. A total of $508 / 523(97.1 \%)$ participants were aware of the cervical cancer and 167/523(31.9\%) could identify HPV as the causative agent. The main source of information was, the media in $336 / 523(64.2 \%)$ cases followed by the medical personnel in $170 / 523(32.5 \%)$ cases. About 314/523(60.0\%) participants had never been screened while 209/523(40.0\%) other had previously been screened. According to the participants' view on barriers to cervical cancer screening, 135/523(25.8\%) cited lack of information, 88/523(16.8\%) mentioned no medical request and 75/523(14.3\%) complained of poverty (Table 2).

On Table 3, we assessed the participant's specific knowledge score on cervical cancer screening tests, risk factors, symptoms and prevention and treatment options available. The knowledge score of available screening tests and the reasons for screening were satisfactory. A majority of participants cited at least $50 \%$ of correct responses. In contrary, 24/523(4.6\%) and 22/523(4.2\%) participants had excellent score for the screening tests and reasons for screening respectively. About 298/523(57.0\%) participants had poor knowledge score of the 
age at first screening for cervical cancer while only 4/523(0.8\%) had excellent knowledge score (Table 3 ). The knowledge score on risk factors and symptoms was similarly distributed with 484(92.5\%) and $39 / 523(7.5 \%)$ participants having poor and good knowledge score respectively. Table 3 shows the knowledge score of the preventive measures to be poor in 480/523(91.8\%) cases and good in 43/523(8.2\%) cases. Similarly, the knowledge score of the treatment options was poor in $379 / 523(72.5 \%)$; satisfactory in $128 / 523(24.5 \%)$ cases and excellent in $16(3.1 \%)$ cases (Table 3$)$.

The overall knowledge score on cervical cancer is shown on table 4 . A total of 490/523(93.7\%) participants had poor knowledge score followed by $32 / 523(6.1 \%)$ with satisfactory score and $1 / 523(0.2 \%)$ with good score.

Table 1: Socio-demographic characteristics of the participants.

\begin{tabular}{|c|c|c|}
\hline Characteristics & Frequency & Percentage (\%) \\
\hline \multicolumn{3}{|l|}{ Age (years) } \\
\hline $25-38$ & 248 & 47.4 \\
\hline $39-52$ & 186 & 35.6 \\
\hline $53-65$ & 89 & 17.0 \\
\hline \multicolumn{3}{|l|}{ Marital status } \\
\hline Married & 320 & 61.2 \\
\hline Single & 148 & 28.3 \\
\hline Divorced & 13 & 2.5 \\
\hline Widow & 42 & 8.0 \\
\hline \multicolumn{3}{|l|}{ Occupation } \\
\hline Housewife & 175 & 33.5 \\
\hline Formal work & 177 & 33.8 \\
\hline Business & 88 & 16.8 \\
\hline No formal work & 83 & 15.9 \\
\hline \multicolumn{3}{|l|}{ Education } \\
\hline No formal & 177 & 33.8 \\
\hline Primary & 95 & 18.2 \\
\hline Secondary & 234 & 44.7 \\
\hline Tertiary & 17 & 3.3 \\
\hline
\end{tabular}


Table 2: Assessment of participants' awareness and barriers to cervical cancer.

\begin{tabular}{lcc}
\hline Determinants & $\begin{array}{c}\text { Frequency } \\
(\mathbf{n = 5 2 3 )}\end{array}$ & $\begin{array}{c}\text { Percentage } \\
\mathbf{( 1 0 0 \% )}\end{array}$ \\
\hline Awareness of cervical cancer & 508 & 97.1 \\
A family member with cancer & 103 & 19.7 \\
Causative agent of cervical cancer & 167 & 31.9 \\
Source of information about cervical cancer & & 75.9 \\
* & & \\
$\quad$ From medical practitioner & 170 & 32.5 \\
$\quad$ From a friend & 124 & 23.7 \\
$\quad$ From the radio/television/internet & 336 & 64.2 \\
Ever screened for cervical cancer & & \\
$\quad$ It is my first time & 314 & 60.0 \\
$\quad$ More than once & 209 & 40.0 \\
Barriers to cervical cancer screening * & & \\
Lack of information & 135 & 25.8 \\
Test procedure embarrassing & 16 & 3.1 \\
Fear of the result & 25 & 4.8 \\
Test procedure painful & 11 & 2.1 \\
My doctor did not request & 88 & 16.8 \\
Poverty & 75 & 14.3 \\
\hline
\end{tabular}

*The total does not make up to 523(100\%)

Table 3: Specific knowledge score of the participants.

\begin{tabular}{lll}
\hline Characteristics & $\begin{array}{l}\text { Frequency } \\
(\mathbf{n = 5 2 3})\end{array}$ & $\begin{array}{l}\text { Percentage } \\
(\mathbf{1 0 0} \%)\end{array}$ \\
\hline Knowledge of screening tests (score/3) & 238 & 45.5 \\
Poor (score 0/3) & 261 & 49.9 \\
Satisfactory (score 1-2/3) & 24 & 4.6 \\
Good ( score 3/3) & 143 & \\
Knowledge of reason for screening (score/3) & 358 & 68.5 \\
Poor ( score 0/3) & 22 & 4.2 \\
Satisfactory ( score 1-2/3) & & \\
Excellent ( score 3/3) & 484 & 92.5 \\
Knowledge of risk factors (score /7) & & \\
Poor ( score <4/7) & & \\
\hline
\end{tabular}




\begin{tabular}{lll}
\hline Good ( score $\geq 4 / 7)$ & 39 & 7.5 \\
Knowledge of the age at first screening (score/2) & & \\
Poor (score 0/2) & 298 & 57.0 \\
Satisfactory (score 1/2) & 221 & 42.3 \\
Excellent (score 2/2) & 4 & 0.8 \\
Knowledge of symptoms (score/9 & & \\
Poor (score 0-4/9) & 484 & 92.5 \\
Good (score 5-9/9) & 39 & 7.5 \\
Knowledge of prevention & & \\
Poor (score < 4) & 480 & 91.8 \\
Good (score $\geq 4)$ & 43 & 8.2 \\
Knowledge of treatment measures (score/3) & & \\
Poor (score 0/3) & 379 & 72.5 \\
Satisfactory ( score 1-2/3) & 128 & 24.5 \\
Excellent ( score 3/3) & 16 & 3.1 \\
\hline
\end{tabular}

Table 4: The overall knowledge score of cervical cancer among participants.

\begin{tabular}{lll}
\hline Total knowledge score & Frequency & Percentage \\
\hline Poor & 490 & 93.7 \\
Satisfactory & 32 & 6.1 \\
Good & 1 & 0.2 \\
Total & 523 & 100 \\
\hline
\end{tabular}

\section{DISCUSSION}

The current study aimed at assessing the knowledge on cervical cancer and screening tests among women in the city of Yaoundé (Cameroon). The majority of participants were aged 25-38 years, married, with secondary school level of education and had formal activity. Similar study in Nepal reported a majority of participants in the age group of 20-29 years who were married and had a secondary level of education or more (Thapa et al., 2018). Most of the participants were at the reproductive age which might be a reason for the large participation in this study. Variation in age groups in both studies might be attributed to the inclusion criteria; in the current study we excluded women less than 25 years.
The majority of our participants were aware of cervical cancer mainly from the media. There are regional variations in the awareness and source of information of cervical cancer. Good level of awareness was reported in Ethiopia (Dulla et al., 2017). In Ghana, more than half women had never heard of cervical cancer and the risk factors (Ebu et al., 2015). Toye et al. (2017) reported the commonest source of information about cervical cancer in Nigeria to be from the medical personnel, media, family members, internet and friends. The current study was conducted in an urban area where media/internet facilities are available which might have influenced the level of awareness about the disease. 
Cervical cancer screening is not a routine test recommended by medical personnel in Yaoundé. Few health care centres occasionally offer screening campaigns. In the present study, few women knew the recommended age and the usefulness of cervical cancer screening. Still in the current study, more than half $(60.0 \%)$ participants had never been screened with the main reasons being: lack of awareness, no medical request and poverty. In Kenya, only $16.4 \%$ respondents had been screened for cervical cancer (Ng'ang'a et al., 2018). The commonest reasons for not undergoing the screening test in some studies were mainly personal factors such as fear of the procedure, cultural or religious reasons, were not ill (Hoque and Hoque, 2009), negligence, fear of discovering a serious disease and deeming it unimportant(Assoumou et al., 2015).

A majority of the participants mentioned at least one test for cervical cancer with the most cited being Pap test (50.7\%). Our finding was in discordance with a study in Uganda which found more than half the respondents $(54.3 \%)$ with no knowledge of any methods of testing (Mukama et al., 2017). In our setting, few health-care centres offer cervical cancer screening services which might be a reason for low participation in the screening procedures despite good knowledge of the Pap test.

The overall knowledge on cervical cancer in this study was good among $0.2 \%$ women, lower than $3.6 \%$ found by Ekane et al. (2015) in Buea (Cameroon). Assessment of specific knowledge of risk factors, symptoms and prevention methods of cervical cancer in this study was also poor. Another study in Nigeria reported a good knowledge of women symptoms and risk factors of cervical cancer (Okunowo et al., 2018). Poor knowledge of risk factors, symptoms and prevention might be attributed to a poor national policy on cervical cancer. Mukama et al. (2017) suggested that cervical cancer awareness campaigns should focus on increasing knowledge of signs and symptoms and risk perception of the disease to encourage screening and facilitate early diagnosis of abnormal cases.
The proportion of women with a good knowledge of cervical cancer risk factors and symptoms differ between studies and could be related to social status and level of education. In the current study, frequently cited risk factors were HPV infection and early sexual activity which was in line with a study among University students in Tamale- Ghana (Der et al., 2018). We also found from the current study that bleeding during sexual intercourse and inter-menstrual bleeding were the most known symptoms. Shah et al. (2012) found menstrual abnormalities and abnormal vaginal discharge as common symptoms known by women in India. Cervical cancer symptoms are similar to other common gynaecologic symptoms of women and may contribute to misdiagnosed cases. Good knowledge of risk factors might be an important step towards primary prevention while knowledge of symptoms might be necessary for seeking medical advice.

The knowledge of preventive measures of cervical cancer in this study was also poor and could be due to poor information about the disease in our community. It is documented that cervical cancer can be prevented using HPV vaccine (Chan and Sidibé, 2016). For better prevention coverage, the Advisory Committee on Immunization Practices (ACIP) had recommended routine vaccination at age 11 or 12 years for females and for males (Meites et al., 2016). In the current study, we found low knowledge of HPV vaccine which is in agreement with Assoumou et al. (2015). HPV vaccination is not well implemented in our setting. Low level of knowledge about the vaccine might be attributed to poor educational information.

\section{Conclusion}

This study suggests a high awareness and poor knowledge on cervical cancer. The media was the main source of information. Less than half of the participants could identify HPV as the causative agent. A majority of the participants had never been screened due to lack of information on the available screening tests. We recommend health education using the media to educate 
women on cervical cancer and the available screening tests.

\section{COMPETING INTERESTS} interests.

The authors declare no competing

\section{AUTHORS' CONTRIBUTIONS}

BW conceived the protocol, interviewed the participants and wrote the manuscript; DBTP participated in the write up, statistical analysis and reviewed the manuscript; PWG participated in the interview of the participants and statistical analysis; JCND study design, reviewed the manuscript; FGN, NDS and NT reviewed the article.

\section{ACKNOWLEDGEMENTS}

The authors are grateful to the women who participated in this study, to the administrations of the YUTH and YOGPH for the logistic. We are also thankful to the personnel of the VIA/VILI and the family planning units of the YUTH and YGOPH units for their collaboration.

\section{REFERENCES}

Abdullahi A, Hassan A, Kadarman N, Saleh A, Baraya YS, Lua PL. 2016. Food safety knowledge, attitude, and practice toward compliance with abattoir laws among the abattoir workers in Malaysia. Int J Gen Med, 9: 79-87. DOI: 10.2147/IJGM.S98436

Assoumou SZ, Mabika BM, Mbiguino AN, Mouallif M, Khattabi A, Ennaji MM. 2015. Awareness and knowledge regarding cervical cancer, Pap smear screening and human papillomavirus infection in Gabonese women. BMC Women's Health, 15: 37. DOI: 10.1186/s12905-015-0193-2

Bruni L, Barrionuevo-Rosas L, Albero G, Serrano B, Mena M, Gómez D, Muñoz J, Bosch FX, de Sanjosé S. 2017. ICO/IARC Information Centre on HPV and Cancer (HPV Information

Centre). Human Papillomavirus and Related Diseases in Cameroon. Summary Report. 2017. Access on the 10 December 2018.
Chan M, Sidibé M. HPV, HIV and cervical cancer. UNIAIDS- WHO Report. 2016: 44.

Der EM, Aduah R, Iddisa BM, Awinboya GA, Nakong NV. 2018. The knowledge and acceptability of cervical cancer Screening among female students in University for Development Studies (Uds) Tamale Campus-Dungu. JAMMR, 27(4): $\quad 1-.9 . \quad$ DOI: 10.9734/JAMMR/2018/40783

Dulla D, Daka D, Wakgari N. 2017. Knowledge about cervical cancer screening and its practice among female health care workers in southern Ethiopia: a cross-sectional study. Int. J. Women's Health, 9: 365-372. DOI: https://doi.org/10.2147/IJWH.S132202

Ebu NI, Mupepi SC, Siakwa MP, Sampselle CM. 2015. Knowledge, practice, and barriers toward cervical cancer screening in Elmina, Southern Ghana. Intern $J$ Women's Health, 7: 31-39. DOI: 10.2147/IJWH.S71797

Ekane GEH, Obinchemti TE, Nguefack CT, Nkambfu DM, Tchounzou R, Nsagha DS, Nkwele GM, Orock GE. 2015. Pap smear Screening, the Way Forward for Prevention of Cervical Cancer? A Community Based Study in the Buea Health District, Cameroon. Open J. Obst. Gynecol, 5: 226-233. DOI: http://dx.doi.org/10.4236/ojog.2015.540 33

Finocchario-Kessler S, Wexler C, Maloba M, Mabachi N, Ndikum-Moffor F, Bukusi E. 2016. Cervical cancer prevention and treatment research in Africa: a systematic review from a public health perspective. BMC Women's Health, 16: 29. DOI: $10.1186 / \mathrm{s} 12905-$ 016-0306-6

Ghittoni R, Accardi R, Chiocca S, Tommasino M. 2015. Role of human papillomaviruses in carcinogenesis. ecancer, 9: $526 . \quad$ DOI: 10.3332/ecancer.2015.52

Hoque E, Hoque M, 2009. Knowledge of and attitude towards cervical cancer among female university students in South Africa. South Afr J Epidemiol Infect, 
2009; 24(1): 21-24. DOI: 10.1080/10158782.2009.11441335

Kassa RT. 2018. Risk factors associated with precancerous cervical lesion among women screened at Marie Stops Ethiopia, Adama town, Ethiopia 2017: a case control study. BMC Res Notes, 11: 145. DOI: 10.1186/s13104-0183244-6

Mbulawa ZZA, Coetzee D, Williamson A-L. 2015. Human papillomavirus prevalence in South African women and men according to age and human immunodeficiency virus status.

BMC Infect Dis, 15: 459. DOI: 10.1186/s12879-015-1181-8

Meites E, Kempe A, Markowitz LE. 2016. Use of a 2-Dose Schedule for Human Papillomavirus Vaccination -Updated Recommendations of the Advisory Committee on Immunization Practices. Morb Mortal Wkly Rep (MMWR), 65: 1405-1408.

DOI: http://dx.doi.org/10.15585/mmwr.mm65 $49 \mathrm{a} 5$

Mukama T, Ndejjo R, Musabyimana A, Halage AA, Musoke D. 2017. Women's knowledge and attitudes towards cervical cancer prevention: a cross sectional study in Eastern Uganda. BMC Women's Health, 17: 9. DOI: 10.1186/s12905-017-0365-3

Ng'ang'a A, Nyangasi M, Nkonge NG, Gathitu E, Kibachio J, Gichangi P, Wamai RG and Kyobutungi C. 2018. Predictors of cervical cancer screening among Kenyan women: results of a nested case-control study in a nationally representative survey. BMC Public Health, 18(3): 1221: 31-40. DOI: https://doi.org/10.1186/s12889-0186054-9

Ogembo JG, Muffih TP, Louise M, Wamai, R, Kemunto R, Welty E, Welty $\mathrm{T}$, Manga, S, Bradford L, Kalmakis K, Sheldon LK. 2014. "Cervical Cancer in Cameroon: A Three Pronged Approach to Increase Awareness, Vaccination, Screening and Treatment" (2014).
UMass Center for Clinical and Translational Science Research Retreat. 90.http://escholarship.umassmed.edu/cts _retreat/2014/posters/90

Okunowoa AA, Daramola ES, Soibi-Harry AP, Ezenwankwo FC, Kuku JO, Okunade KS, Anorlu RI. 2018. Women's knowledge of cervical cancer and uptake of Pap smear testing and the factors influencing it in a Nigerian tertiary hospital. J. Cancer Research and Practice, 5(3): 105-111. DOI: https://doi.org/10.1016/j.jcrpr.2018.02.0 01

Sah SK, González JV, Shrestha S., Adhikari A, Das Manandhar KD , Yadav SB, Stein DA, Gupta BP and Picconi MA. 2018. Human papillomavirus genotype distribution in cervical cancer biopsies from Nepalese women. Infect. Agents and Cancer, 13: $4 . \quad$ DOI: 10.1186/s13027-018-0176-7

Shah V, Vyas S, Singh A, Shrivastava M. 2012. Awareness and knowledge of cervical cancer and its prevention among the nursing staff of a tertiary health institute in Ahmedabad, Gujarat, India. Ecancermedicalscience, 6: 270. DOI: 10.3332/ecancer.2012.270

Thapa N, Maharjan M, Petrini MA, Shah R , Shah S , Maharjan N, Shrestha N, Cai H. 2018. Knowledge, attitude, practice and barriers of cervical cancer screening among women living in mid-western rural, Nepal. J. Gynecol Oncol, 29(4): e57. DOI: $10.3802 /$ jgo.2018.29.e57

Toye MA, Okunade KS, Roberts AA, Salako O, Oridota ES, Onajole AT. 2017. Knowledge, perceptions and practice of cervical cancer prevention among female public secondary school teachers in Mushin local government area of Lagos State, Nigeria. Pan African Med. J, 28: $221 . \quad$ DOI: 10.11604/pamj.2017.28.221.13980

WHO/International Agency for Research on Cancer (IARC). 2018. Latest global cancer data: Press release, $\mathrm{N}^{\circ} 263$. 